\title{
Awareness and practice of biomedical waste management among healthcare providers in a Tertiary Care Hospital of West Bengal, India
}

\section{Sourya Kanti Das, Romy Biswas}

Departments of Radiodiagnosis and ${ }^{1}$ Community Medicine, North Bengal Medical College,

Darjeeling, West Bengal, India

Address for the Correspondence: Dr. Romy Biswas,

Professor's Quarter No. A-6, North Bengal Medical College Campus, P. O - Sushrutanagar, Darjeeling - 734012 West Bengal, India. E-mail: romyraktim@yahoo.com

Access this article online
Website: www.jmmedph.org
DOI: 10.4103/2230-8598.179755
Quick response code:

Background: Biomedical waste (BMW) is waste generated during diagnosis, treatment, or immunization of human beings or animals or in research activities. BMW is hazardous and can be injurious to humans or animals and deleterious to environment. Effective management of BMW is a legal as well as a social responsibility. Objectives: To assess the knowledge and practice regarding hospital waste management among healthcare providers of a tertiary care hospital. Materials and Methods: The study was conducted in the Departments of General Medicine, Surgery, Gynecology and Obstetrics, and Radiotherapy among 198 different hospital staff within 3 months with the help of a predesigned and pretested interview schedule to elicit the knowledge of BMW management. An observatory checklist is used to find out practices regarding BMW management prevailing in the above wards and staff of the hospital. Results: Majority $(60.6 \%)$ of the study population belonged to the age group of $21-30$ years. About one-third of the total study population were junior doctors and nurses. $35.8 \%$ worked for 1 year in the hospital, and $29.8 \%$ worked within $2-5$ years. All the participants had heard about BMW management, but only $1.5 \%$ had formal training. $6.6 \% \mathrm{knew}$ about five-color coding used for segregation of waste with red, black, yellow, blue bags and white puncture proof container. $31.3 \%$ knew correct disposal of sharps. All the participants knew about the use of personal protective measures while handling BMW and used in most of the time. $70.2 \%$ of respondents knew the use of gloves and mask together. In $33.3 \%$ of observation, it was seen that syringes were reused for the same patient. Four colored bins were used most of the time in the above-studied wards. Conclusion and Recommendation: The above study revealed certain paucity of knowledge among the healthcare providers in the field of BMW management which adversely affected their practice. There should be regular comprehensive training programs regarding BMW management for all level of workers and strict implementation of them.

Key words: Biomedical waste, healthcare providers, knowledge, practice

\section{INTRODUCTION}

Biomedical waste (BMW) is a broader term applied to "any waste that is generated during diagnosis, treatment, or immunization of human beings or animals, or in the research activities pertaining to or in the production or testing of biological and includes ten categories mentioned in Schedule I of the Government of India's BMW (management and handling) rules 1998."[1]

This is an open access article distributed under the terms of the Creative Commons AttributionNonCommercial-ShareAlike 3.0 License, which allows others to remix, tweak, and build upon the work non-commercially, as long as the author is credited and the new creations are licensed under the identical terms.

For reprints contact: reprints@medknow.com

How to cite this article: Das SK, Biswas R. Awareness and practice of biomedical waste management among healthcare providers in a Tertiary Care Hospital of West Bengal, India. Int J Med Public Health 2016;6:19-25. 
The waste produced in the course of healthcare activities carries a higher potential for infection and injury than any other type of waste.

Expansion of health care facilities with the advancement of modern technologies as well as the recent trend of using disposables has led to a high burden of health care-related wastes. Since the last three decades, unregulated handling of BMW is emerging as a serious threat to human health and safety, and many researchers have documented this as a priority area. ${ }^{[2,3]}$

The absence of proper waste management, lack of awareness about the health hazards from BMWs, insufficient financial and human resources, and poor control of waste disposal are the most critical problems faced with healthcare waste. ${ }^{[4]}$ The hazardous impact of medical waste on us and environment is enhanced manifold if the appropriate handling of these wastes is not adopted.

Improper disposal methods of these wastes may lead to the spread of serious and harmful diseases such as AIDS, hepatitis B and $\mathrm{C}$, and tuberculosis (TB) among the healthcare personnel, waste handlers, patients and their visitors, and community where the waste is indiscriminately deposited. ${ }^{[5]}$

Hospital-acquired infections have been estimated at $10 \%$ of all life-threatening diseases in the Southeast Asia region and have been identified as one of the indicators for the management of waste. ${ }^{[6]}$

There are specific guidelines for segregation and management of BMW. The law envisages schedule, requisite BMW treatment facilities such as incinerator, autoclave, microwave system for the treatment of waste, or ensure requisite treatment of waste at a common waste treatment facility or any other waste treatment facility. ${ }^{[1]}$ The awareness of these laws among the general public as well as the development of policies and enforcement that respect those laws are essential.

Although some Indian studies have identified gaps at local levels, there is no systematic effort to collect data from different parts of the country. ${ }^{[7,8]}$

Effective management of BMW is not only a legal necessity but also a social responsibility. The scenario of awareness and practice regarding BMW management in India is still lacking. ${ }^{[9-11]}$

A strong emphasis on cleanliness and systemic disposal of all wastes including hospital waste is aimed by the Government of India and has been launched as the "Swachh Bharat" mission with a goal to make India "cleaner and greener" to create a better livable atmosphere.

With this background, the present study has been conducted with the objectives of assessing knowledge and practices of doctors, nurses, laboratory technicians, and sanitary staff regarding BMW management of a teaching institution that may help the respective authorities and society to develop further strategy for improving the situation in future. The objectives of the study are:
- To assess the knowledge among the different healthcare providers regarding BMW, its segregation, color coding, and management in the tertiary care hospital

- To find out the practice regarding management of BMWs by the health personnel in the tertiary care hospital.

\section{Hospital profile}

This study was conducted in the preselected departments of North Bengal Medical College and Hospital. This teaching as well as tertiary care hospital is affiliated to the West Bengal University of Health Sciences with the undergraduate and postgraduate teaching of medical profession and situated in Siliguri. It is a 599-bedded hospital having specialty outdoor and indoor facilities of different departments such as medicine, surgery, orthopedics, gynecology and obstetrics, pediatrics, ophthalmology, pathology, and microbiology.

This hospital also possesses almost all the high-edge equipment and facilities for patient care. A huge number of people from adjacent districts of Darjeeling as well as dwellers of Sikkim, Nepal, Bhutan, Bihar, Assam, and Northeast depend totally on this tertiary care health facility for treatment purposes.

\section{MATERIALS AND METHODS}

The study was an observational, cross-sectional, hospital-based study conducted with a duration of 3 months from December 2014 to March 2015 in the Departments of General Medicine, Surgery, Emergency, Gynecology and Obstetrics, and Radiotherapy of North Bengal Medical College and Hospital among different level of healthcare providers such as junior doctors, nursing staff, laboratory technicians, sweepers, and waste handlers in the respective departments.

There are 493 healthcare providers in the above-mentioned wards and indoors among the above-mentioned groups of participants. Forty percent (198 participants) of them were taken as study population by convenient sampling. All willing participants were informed about details regarding the purpose of this study, and prior informed verbal consent was taken from each of them.

Data collection was started after obtaining approval from the Ethics Committee of North Bengal Medical College and Hospital. The data collection was done by interview technique using pretested, semi-structured schedule consisting of two parts. Part 1 includes the basic profile of the participants containing details of various sociodemographic variables, such as age, gender, residence, working status, working place, and working period. Part 2 consists of questions about knowledge on BMW, its management, segregation, color coding, categories of BMWs, solution used for disinfection, diseases that can spread from BMWs, personal protective measures (PPM) to be used, permanent disposal methods, etc.

An observatory checklist was used to collect data on practices regarding BMW. 
Six visits in each of the prefixed wards on 3 consecutive days -3 visits in the morning and 3 visits in the afternoon were made to observe the practice of BMW segregation and management among the health care persons. Study subjects were also assured of the confidentiality and anonymity of their identity throughout the study.

\section{RESULTS}

\section{Respondent's profile}

It is revealed from Table 1 that among a total of 198 respondents, $65.2 \%$ were females and the rest $34.8 \%$ were males. The majority $(60.6 \%)$ of the study population belonged to the age group of 21-30 years. Only $1 \%$ of the subjects were below the age of 20 years, $35.8 \%$ of the subjects were engaged in housekeeping. About one-third of the total study population were junior doctors and nurses. The majority (35.8\%) worked for 1 year in the hospital, and $29.8 \%$ worked within $2-5$ years.

Among the whole study population, minimum age of any participant is 18 years and maximum is 65 years. The mean of age of the total subjects is 31.80 years with standard deviation 10.34 .

\section{Knowledge about biomedical waste management}

About $58.1 \%$ of the study subjects resided within campus area and the rest outside it. All of them had heard about BMW and its management, but only $1.5 \%$ of the subjects had formal training, and $30.8 \%$ of them knew about BMW rules $1998.77 .3 \%$ of the subjects knew that posters were already present in their working area.

Figure 1 shows that only $6.6 \%$ of them knew about five-color coding used for segregation of waste with red, black, yellow, blue

\begin{tabular}{lc} 
Table 1: Profile of respondents & \\
\hline Variables & Frequency (\%) \\
\hline Gender & \\
Male & $69(34.8)$ \\
Female & $129(65.2)$ \\
Age in years & \\
$\leq 20$ & $2(1.0)$ \\
$21-30$ & $120(60.6)$ \\
$31-40$ & $37(18.7)$ \\
$41-50$ & $21(10.6)$ \\
$51-60$ & $18(9.1)$ \\
Working status & \\
Junior doctor & $56(28.3)$ \\
Nurses & $58(29.3)$ \\
Laboratory technicians & $13(6.6)$ \\
Housekeeping staff & $71(35.8)$ \\
Working period (years) & \\
$>1$ & $71(35.8)$ \\
$2-5$ & $59(29.8)$ \\
$6-10$ & $30(15.2)$ \\
$11-20$ & $12(6.1)$ \\
$>20$ & $26(13.1)$ \\
Total & $198(100.0)$ \\
\hline
\end{tabular}

bags and white puncture proof container. On the other hand, $37.8 \%$ and $40.4 \%$ of them had the knowledge of 4 color codes and 3 color codes, respectively. $0.5 \%$ of them were unaware about any color coding. 36.4\% know that bleaching solution can be used for the disinfection purpose whereas $18.7 \%$ know that $1 \%$ hypochlorite solution is used for disinfection. However, about $32.8 \%$ did not know about any solution to be used for disinfection purpose.

$31.3 \%$ of the participants knew correctly that sharps are to be segregated in white-colored puncture proof container and $27.8 \%$ and $16.6 \%$ participants' preferred black and blue plastic bags for disposal of sharps, respectively. $4.5 \%$ of the participants knew about correct bag for disposal of intravenous sets and tubings.

All the participants agreed that harmful and infectious diseases can spread through BMWs.

41.4\% opined that HIV/AIDS can be transmitted through BMW followed by $37.9 \%$ and $17.7 \%$ participants who thought hepatitis $\mathrm{B}, \mathrm{C}$, and TB can be transmitted, respectively.

All the subjects knew about the use of PPM while handling BMW. $70.2 \%$ of the respondents knew the use of both gloves and mask together. $27.2 \%$ participants knew about the use of gloves, mask, and cap simultaneously.

$37.9 \%$ of them did not have any idea about in which colored bins the cytotoxic drugs should be disposed. $32.8 \%$ replied with the black colored plastic bag, but $29.3 \%$ of them uttered wrong colored bags. Infectious BMWs can be kept within hospital premises for more than $6 \mathrm{~h}$ according to $33.9 \%$ of respondents. Table 1 reveals that only $3.5 \%$ healthcare providers knew about the maximum time limit was set to $48 \mathrm{~h}$ by national authorities.

Table 2 reveals the knowledge of the study subjects regarding BMW management. All the participants heard about BMW management. Only $30.8 \%$ of the participants knew about BMW rules, and $62.6 \%$

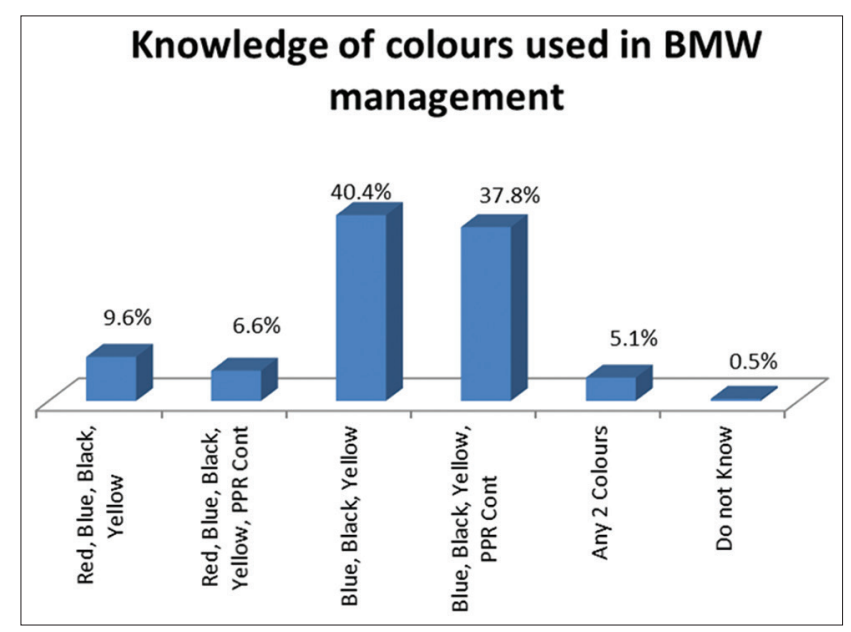

Figure 1: Bar diagram showing awareness regarding color coding for segregation of biomedical wastes among subjects 
participants recognized the symbol. $17.6 \%$ of the participants knew all the ten categories of BMW.

$67.7 \%$ of the participants knew about the permanent disposal methods of BMW, but $84.3 \%$ felt the necessity of disinfection of wastes.

Awareness regarding BMW rules varied among different workers, and it is found to be statistically significant (Pearson Chi-square $=41.406$, $\mathrm{df}=3, P=0.000)$ from Table 3.

\section{Practice of biomedical waste management among the healthcare providers}

Seventy-two observatory visits were made with a checklist in six different wards. Six observations were done in an emergency, medicine, and surgery indoors each in different male and female wards. Six observations were done in the Departments of Gynaecology and Obstetrics and radiotherapy each. Three visits were done both in the morning and evening of the duration of half an hour approximately without prior intimation within 1 month using a checklist to observe the practice regarding management of BMW among all categories of healthcare providers.

In $33.3 \%$ of observations, it was seen that syringes are reused for the same patient but in $25 \%$ of observation, syringes are reused for different patients also. Almost all the on-duty nursing staff agreed that all the intramuscular (IM) needles and syringes and those, which are contaminated with blood or other body fluids, are never reused, and it contributed to $41.7 \%$. In the wards where the syringes were reused for the same patients, the syringes are washed with normal saline (NS) only and in cases where the syringes are used for different patients; the syringes were dipped into the disinfectant solution for a certain period and then sterilized by boiling. Disinfection with hypochlorite was seen in one-quarter of the visits and $11.1 \%$ with other disinfectants. These findings are observed in Table 4

Posters showing color coding for segregation of BMWs were provided by the authority. This institution has tie up with a private waste removal company named Greenzen Bio. Pvt. Ltd., for collection, removal, transport, and permanent disposal of all kinds of BMWs. In each and every ward, there are posters and/or guidelines in working areas except in the Radiotherapy ward, where no posters or guidelines were displayed in the working areas. There was no poster for red color code in any of the wards of the hospital and the guidelines and picture of waste container for disposal of BMWs in the black color-coded posters are wrongly printed, which is leading to an erroneous practice for the same.

In the wards, only black-, blue-, and yellow-colored plastic bags are found along with white translucent puncture proof containers but in none of the above-mentioned wards any red-colored plastic bag was found. On the contrary, in the radiotherapy department, no plastic bags were there, but bins were found in the daycare chemotherapy room. A white puncture proof container was present but never used. All kinds of wastes were deposited in the bins and then thrown

\begin{tabular}{l} 
Table 2: Knowledge of biomedical waste \\
management among study population \\
\hline Content area
\end{tabular}

Content area $n(\%)$

Heard about BMW $198(100)$

Aware of act on BMW rules

Knows about the biohazard symbol

Knows ten categories of BMW

Guidelines provided for color coding in workplace

Aware of the puncture-proof container for sharps

Aware of correct bag for disposal of cytotoxic drugs (black)

Aware of correct bag for intravenous sets, catheters, and tubes

HIVIAIDS can be transmitted through BMW

Hepatitis B/C can be transmitted through BMW

Personal protective measures necessary for handling BMW

Knows about permanent disposal methods of BMW

Necessity of disinfection of biomedical waste

Knows about disinfection of BMW by bleaching solution

Maximum time of BMWs can be kept in hospital premises (48 h)

BMW $=$ Biomedical waste, HIV = Human immunodeficiency virus

\begin{tabular}{|c|c|c|c|}
\hline \multirow[t]{2}{*}{ Working status } & \multicolumn{2}{|c|}{$\begin{array}{c}\text { Awareness about } \\
\text { BMW rules (\%) }\end{array}$} & \multirow[t]{2}{*}{$\begin{array}{c}\text { Total } \\
\text { number }(\%)\end{array}$} \\
\hline & $\begin{array}{l}\text { Present } \\
\text { number }\end{array}$ & $\begin{array}{l}\text { Absent } \\
\text { number }\end{array}$ & \\
\hline Junior doctor & $27(48.2)$ & $29(51.8)$ & $56(100)$ \\
\hline Nurse & $25(43.1)$ & $33(56.9)$ & $58(100)$ \\
\hline Laboratory technician & $7(53.8)$ & $6(46.2)$ & $13(100)$ \\
\hline House keeper & $2(2.8)$ & $69(97.2)$ & $71(100)$ \\
\hline Total & $61(30.8)$ & $137(69.2)$ & $198(100)$ \\
\hline
\end{tabular}

Pearson Chi-square $=41.406, \mathrm{df}=3, P=0.000 . \mathrm{BMW}=$ Biomedical waste

\begin{tabular}{|c|c|c|c|c|}
\hline Color of bags & $\begin{array}{c}\text { Emergency } \\
(n=18) \%\end{array}$ & $\begin{array}{l}\text { Medicin } \\
(n=18) \%\end{array}$ & $\begin{array}{c}\text { Surgery } \\
(n=18) \%\end{array}$ & $\begin{array}{l}G \text { and } O \\
(n=12) \%\end{array}$ \\
\hline Yellow & $18(100)$ & $6(33.3)$ & $17(94.4)$ & $5(41.7)$ \\
\hline Black & $6(33.3)$ & $0(0)$ & $12(66.7)$ & $6(50)$ \\
\hline Blue & $6(33.3)$ & $0(0)$ & $12(66.7)$ & $7(58.3)$ \\
\hline PPR container & $18(100)$ & $18(100)$ & $17(94.4)$ & $6(50)$ \\
\hline
\end{tabular}

In radiotherapy ward, no bags were in seen in six observatory visits.

$\mathrm{G}$ and $\mathrm{O}=$ Gynecology and obstetrics, PPR = Puncture proof container

indiscriminately out of the department in free, open land nearby. No segregation, disinfection, proper packing, and storage were done following/according to the BMW rules 1998.

No bins were found to be covered with lid; rather, all of them were placed openly in all (of) the wards. In about $50 \%$ of the observation, duty staffs placed the infected BMWs in the disinfectant solution as per the BMW rules 1998. In all the wards, priority was given to disposal of the sharps, and disinfection with hypochlorite $(1 \%)$ or 
other solution was done. In practice, it was observed that most of the time in all wards, gloves and masks were used as PPM.

During observatory visits, radiotherapy department had no colored bags for BMW. In emergency and medicine wards, there was the universal use of yellow bins and white puncture proof container, but there was no use of blue and black bins in medicine wards. In surgery, all the bins were seen to be used in various proportions. In about $50 \%$ of the visits to gynecology wards, all bins were used.

\section{DISCUSSION}

A descriptive, hospital-based study was conducted among 198 healthcare providers including junior doctors, nurses, technicians, and waste handlers of a teaching institution to find out the knowledge and practice regarding BMW and its management.

The minimum age of the study population is 18 years. Although all have heard about BMW, only $30.8 \%$ had formal training. $37.8 \%$ had knowledge of four color codes for disposal. $41.4 \% \mathrm{knew}$ HIV/AIDs can be transmitted through BMWs. All of them knew about the uses of PPM.

In observatory sessions, it was seen that only black-, blue-, and yellow-colored bins were found, but red-colored bins did not exist. No bins were found to be covered.

All of the participants have heard about BMW management. It is similar to studies carried by Chudasama et al. ${ }^{[12]}$ in a tertiary care hospital in Rajkot and Madhavi et al. in Khammam, ${ }^{[13]}$ who found $95.4 \%$ and $94.8 \%$ of the participants were aware of BMW, respectively.

Nearly $30.8 \%$ of the subjects knew about BMW rules which were $51.4 \%$ in the study by Chudasama et al. ${ }^{[12]}$ Awareness in this regard was $72 \%, 80 \%, 75 \%, 67.8 \%$, and $94.4 \%$ in studies conducted in Kothamangalam, ${ }^{[14]}$ Amritsar, ${ }^{[15]}$ Delhi, ${ }^{[11]}$ Khammam, ${ }^{[13]}$ and West Bengal, ${ }^{[16]}$ respectively.

About $1.5 \%$ of the total study population had received formal training on BMW management, which is $44.7 \%$ and $16.3 \%$ in studies of Rajkot ${ }^{[12]}$ and Kothamangalam, ${ }^{[14]}$ respectively.

In the Rajkot study, ${ }^{[12]}$ approximately $96.5 \%$ of subjects knew that different colored bags were used for segregation of BMWs whereas almost all the participants $(100 \%)$ from our study opined the same. Only $6.6 \%$ knew correctly about all the colors used for coding. Results from a study conducted in a tertiary care hospital of West Benga ${ }^{[6]}$ among the junior doctors show that nearly $76.4 \%$ of the subjects knew about various types of color-coded bags for collection of BMW. In a separate study in Rajkot, ${ }^{[12]} 84.4 \%$ of participants identified all colored bags used for BMW collection. A study conducted by Imtiaz et al., ${ }^{[17]}$ in a tertiary care hospital, Uttar Pradesh, suggested that correct knowledge regarding the same was adequately sufficient across all 4 groups of healthcare personnel which was similar to another study by Mathur et al. ${ }^{[18]}$ in Lucknow.
In a study conducted in Dhule (Maharashtra), ${ }^{[19]}$ results show that a maximum number of nurses $(80.2 \%)$ and $18.9 \%$ of sanitary workers and $42.8 \%$ technicians correctly had the knowledge of blue or transparent white container for disposal of sharp wastes. However, in our study, it was found that $45.9 \%$ of subjects had the knowledge of the same and identified the puncture proof white container correctly.

Almost $84.3 \%$ of the healthcare providers had knowledge about the necessity of disinfection. Among them, 36.4\% participants suggest that bleaching solution is used for the purpose whereas $32.8 \%$ do not now about the solution used and $18.7 \%$ believe it to be hypochlorite $(1 \%)$ solution.

Nearly $77.3 \%$ of the healthcare providers knew that posters with different color codings were already present in their working area, displaying the name of different bins for BMWs. On the other hand, the study carried out by Chudasama et al. in a tertiary care hospital in Rajkot concluded that $81.2 \%$ of study population agreed to the fact.

The study conducted in Rajkot ${ }^{[12]}$ depicted that about $40.4 \%$ of the subjects knew about BMW management categories, which is much higher in comparison with the current study, where it is found to be only $11.6 \%$. In contrary to the present study, about $52.2 \%$ and $55.9 \%$ of the study population in two studies conducted by Madhavi et al. in Khammam ${ }^{[13]}$ and Basu et al. ${ }^{[16]}$ among interns in West Bengal have a correct knowledge of the same. In another study conducted by Madhukumar and Ramesh in Bangalore, ${ }^{[20]}$ it was only $38.5 \%$.

All the subjects acknowledged that various kinds of harmful and infectious diseases can spread through BMWs. With 41.4\% HIV/AIDS tops the list, followed by hepatitis B/C, TB, and other infectious diseases with $37.9 \%, 17.7 \%$, and $3 \%$, respectively. This is in contrast to the study by Chudasama et al. ${ }^{[12]}$ who pointed out that $74.5 \%, 56.0 \%, 8.5 \%$, and $53.2 \%$ participants, respectively, concluded that HIV/AIDS, hepatitis B, TB, and other infectious disease can spread through BMWs following the above-mentioned sequence and can cause harm to mankind and the environment.

About $64 \%$ and $65.2 \%$ of the respondents were aware of the correct Biohazard symbol in studies by Sanjeev et al. ${ }^{[14]}$ and Madhavi et al. ${ }^{[13]}$ respectively, which is similar to $61.6 \%$ response rate from this study.

Only $3.5 \%$ of the respondents knew the correct maximum time limit of keeping the BMWs around hospital premises.

About $31.3 \%$ respondents knew the sharps should be deposited in white-colored Puncture proof (PPR) container followed by $16.7 \%$ participants who suggested blue-colored plastic bag for the same purpose.

About $37.9 \%$ of health care personnel did not have any idea regarding disposal of cytotoxic drugs whereas $32.8 \%$ agreed that black-colored plastic bags should be used for this purpose.

\section{Practice}

Segregation of BMW at the site of generation is found to be nil among our study population. On the contrary, the study by 
Chudasama et al. ${ }^{[12]}$ figured out that the correct response for the same was as high as $86.9 \%$. Studies conducted in Chennai ${ }^{21]}$ and Davangere $^{[22]}$ also found out the same to be $82.4 \%$ and $70 \%$, respectively.

BMW management according to color coding is also found to be nil among the study subjects. This may be due to the presence of considerable proportion of cleaning/sanitary staff as respondents. In some other studies in Kothamangalam, ${ }^{[14]}$ Chennai, ${ }^{[21]}$ and Davangere, ${ }^{[22]}$ it was found that, respectively, $14 \%, 28 \%$, and $27 \%$ respondents chose any plastic bag for segregation of biomedical waste.

Fifty percent of the participants destroyed the needles after use either by cutter, shredder, or mere by mutilation. In a study conducted in Dhaka, Bangladesh, by Sarker et al. . $^{[23]}$ destruction of needles was done in $26.1 \%, 19.5 \%, 22.7 \%$, and $21.6 \%$ by medical doctors, nurses, technologists, and cleaning staff, respectively.

In $33.3 \%$ cases, needles were reused for the same patient after NS wash, and in $25 \%$ cases, it is even reused for different patients after dipping it into disinfectant solution and then boiling it in the sterilizer within the ward only. Needles and syringes, after intramuscular use or when visibly soiled with blood or body fluid, then were never reused again.

In only $25 \%$ and $11.1 \%$ findings disinfection of infected BMWs, particularly the sharps are done using hypochlorite solution and some other disinfectant solution, respectively before disposal. In a study in Rajkot by Chudasama et al., ${ }^{[12]}$ the same finding counted to be $84.8 \%$.

In any ward, there was no provision for maintenance of any BMW record which is just opposite to finding of Chudasama et al., ${ }^{[12]}$ where the researchers noticed it be $74.5 \%$ for the same. The condition of the BMW injury reporting was also the same. There was no record of any injury. Moreover, none of the respondents ever knew how to notify the authority and officially record a BMW related injury. Chudasama et al. ${ }^{[12]}$ in their study depicted the same to be $17.4 \%$.

In all the wards, no bin was covered with lid; rather, all of them were kept open. All kinds of waste were collected in the bins and thrown in open land nearby in radiotherapy ward. PPR container in both gynecology and obstetrics ward and radiotherapy department was never used for the purpose and remained empty at a corner of the working area.

Gloves and masks were the PPM used by all subjects; however, in addition, apron was used in case of maternity (gynecology and obstetrics) wards. In a Palestinian Hospital study, there were no protective equipment or clothes available for most workers. ${ }^{[24]}$ Chudasama et al. in his Rajkot study ${ }^{[12]}$ found $84.8 \%$ used PPM while handling BMW.

Thus, this study enlightens us regarding the existing knowledge and practices of various levels of health care professionals regarding BMW management in North Bengal Medical College and Hospital, a tertiary healthcare center in West Bengal, India. The researchers recommend similar studies should therefore be performed with a large sample size. The need for more research and accurate, authentic data to provide an evidence base for the future decision-making and for drafting a proper and up to date guideline is highlighted.

\section{CONCLUSION AND RECOMMENDATION}

The study revealed a lack of knowledge in different tiers of healthcare providers which adversely affects their practice. Healthcare professionals and government should work together to develop standard feasible policies for BMW management. Even the color-coded bags were there, it was not used; hence, there should be strict implementation of BMW rules for all health care providers and facilities to ensure safety and protection to all health care staff and should be mandatory for all to be trained in this regard. Regular intensive training programs should be held, especially for paramedical and housekeeping staff to develop their practical skill. Moreover, adequate supplies and equipment should be available in all departments to take care of wastes. It is likely that public sectors and private medical care centers should also be incorporated into this matter as soon as possible.

\section{Financial support and sponsorship}

Nil.

\section{Conflicts of interest}

There are no conflicts of interest.

\section{REFERENCES}

1. Government of India. The Ministry of Environment and Forests. Biomedical Waste (Management and Handling) Rules. 1998. Extraordinary, Part II, Section3, Subsection (ii). The gazette of India, No. 460, 27 Jul 1998. Available from: http://envfor.nic.in/legis/hsm/biomed.html. [Last accessed on 2016 Mar 15].

2. Mostafa GM, Shazly MM, Sherief WI. Development of a waste management protocol based on assessment of knowledge and practice of healthcare personnel in surgical departments. Waste Manag 2009;29:430-9.

3. Rutala WA, Mayhall CG: Medical waste. Infect Control Hosp Epidemiol 1992;13:38-48.

4. Plianbangchang PH. W.H.O. Publication; "A Report on Alternative Treatment and Non-Burn Disposal Practices"; Safe Management of Biomedical Sharps Waste in India.

5. Gupta S, Boojh R. Biomedical waste management practices in Balrampur Hospital, Lucknow, India. Waste Manag Res 2006;24:584-91.

6. Ozbek M, Sanin FD. A study of the dental solid waste produced in a school of dentistry in Turkey. Waste Manag 2004;24:339-45.

7. Townend WK. Healthcare Waste Management: Policies, Legislations, Principles and Technical Guidelines, Waste Management World Magazine. Vol. 10; 2009. Available from: http://www.waste-management-world.com. [Last accessed on 2016 Mar 15].

8. Sharma S. Safe and newer injection technologies. J Indian Med Assoc 2005;103:215-6, 218, 221.

9. Pandit NB, Mehta HK, Kartha GP, Choudhary SK. Management of bio-medical waste: Awareness and practices in a district of Gujarat. Indian J Public Health 2005;49:245-7.

10. Rao PH. Report: Hospital waste management - Awareness and practices: A study of three states in India. Waste Manag Res 2008;26:297-303. 
11. Kishore J, Goel P, Sagar B, Joshi TK. Awareness about biomedical waste management and infection control among dentists of a teaching hospital in New Delhi, India. Indian J Dent Res 2000;11:157-61.

12. Chudasama RK, Rangoonwala M, Sheth A, Misra SK, Kadri AM, Patel UV. Biomedical waste management: A study of knowledge, attitude and practice among health care personnel at tertiary care hospital in Rajkot. J Res Med Dent Sci 2013;1:17-22.

13. Madhavi KV, Reddy BC, Ravikumar BP. Awareness Regarding Biomedical Waste Management among Interns in a Tertiary Health Care Hospital, Khammam. J Evol Med Dental Sci. 2:5360-5365.

14. Sanjeev R, Kuruvilla S, Subramaniam R, Prashant PS, Gopalakrishnan M. Knowledge, attitude, and practices about biomedical waste management among dental healthcare personnel in dental colleges in Kothamangalam: A cross-sectional study. Health Sci 2014;13:1-12.

15. Narang RS, Manchanda A, Singh S, Verma N, Padda S. Awareness of biomedical waste management among dental professionals and auxiliary staff in Amritsar, India. Oral Health Dent Manag 2012;11:162-8.

16. Basu M, Das P, Pal R. Assessment of future physicians on biomedical waste management in a tertiary care hospital of West Bengal. J Nat Sci Biol Med 2012;3:38-42.

17. Imtiaz D, Gupta SB, Singh JP, Shrotriya VP, Malik S. Assessment of knowledge of hospital staff regarding biomedical waste management in a tertiary care hospital in Uttar Pradesh. Sch J Appl Med Sci 2014;2:1070-4.

18. Mathur V, Dwivedi S, Hassan M, Misra R. Knowledge, Attitude, and practices about biomedical waste management among healthcare personnel: A cross-sectional study. Indian J Community Med 2011;36:143-5.

19. Patil SP, Tambe MP, Patil PJ, Bhagwat VR. Awareness of Healthcare Workers Regarding Biomedical Waste Management (BMW) At Tertiary Care Government Hospital In Dhule (Maharashtra). Natl J Integr Res Med 2013;4:74-9.

20. Madhukumar S, Ramesh G. Study about awareness and practices about health care wastes management among hospital staff in a medical college hospital, Bangalore. Int J Basic Med Sci 2012;3:7-11. Available from: $\quad$ http://www.ijbms.com/wp-content/uploads/2012/10/suwarnamadhukumar.pdf. [Last accessed on 2016 Mar 15].

21. Charania ZK, Ingle NA. Awareness and practices of dental care waste management among dental practitioners in Chennai city. J Contemp Dent 2011;1:15-21.

22. Sudhir KM. Awareness and practices about dental health care waste management among dentists of Davangere City, Karnataka. J Indian Assoc Public Health Dent. 2006;8:44-50.

23. Sarker MA, Harun-Or-Rashid M, Hirosawa T, Abdul Hai MS, Siddique MR, Sakamoto J, et al. Evaluation of knowledge, practices, and possible barriers among healthcare providers regarding medical waste management in Dhaka, Bangladesh. Med Sci Monit 2014;20:2590-7.

24. Al-Khatib IA. Occupational safety of cleaning personnel in Palestinian district hospitals. East Mediterr Health J 2006;12:637-52. 